\title{
An evaluation and exploration of Irish food-service businesses' uptake of and attitudes towards a voluntary government-led menu energy (calorie) labelling initiative
}

\author{
Sarah Fitzgerald ${ }^{1, *}$, Lauri Gilgan ${ }^{1}$, Mary McCarthy², Ivan J Perry ${ }^{1}$ and Fiona Geaney ${ }^{1}$ \\ 'School of Public Health, University College Cork, Western Gateway Building, Western Road, Cork, Republic of \\ Ireland: ${ }^{2}$ Cork University Business School, University College Cork, Cork, Republic of Ireland
}

Submitted 21 December 2017: Final revision received 27 April 2018: Accepted 22 June 2018: First published online 16 August 2018

\begin{abstract}
Objective: To investigate the uptake of and attitudes towards a voluntary government-led energy (calorie) menu labelling initiative in Ireland among a representative sample of food-service businesses and to inform further actions that may need to be undertaken to facilitate successful implementation.

Design: A mixed-methods approach, incorporating a national telephone survey, structured observation visits and semi-structured interviews.

Setting: Twenty-six counties in the Republic of Ireland.

Subjects: A random selection of food-service businesses ( $n$ 604) participated in the telephone survey. Businesses which indicated that they did display calories were selected to participate in structured observation visits ( $n$ 42), along with a random sample ( $n$ 38) of businesses that did not display calories. A purposive sample of thirteen food-service business owners who participated in the telephone survey participated in semi-structured interviews.

Results: In the telephone survey, $7 \%$ ( $n$ 42) of food businesses reported displaying calories and the observation visits revealed that of these businesses, $10 \%(n 4)$ were not displaying calorie information. Three major themes emerged from the semi-structured interviews: uncertainty, impact on business and consumer nutrition knowledge. Participants expressed concerns regarding inaccuracies in the calorie information, cost and time implications, mistrust in the food-service industry and poor nutritional knowledge among consumers. These concerns impeded the implementing of calorie menu labelling.

Conclusions: A multifactorial approach that incorporates guidance and support (training/tax incentives), practical assistance (user-friendly calorie calculation software), a reasonable legislative structure and a standardised monitoring system is needed to facilitate the successful implementation of calorie menu labelling.
\end{abstract}

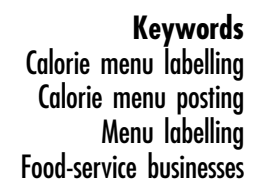

The growing prevalence of overweight and obesity is a preeminent global public health challenge of the 21st century. This is due to the associated morbidity and mortality, mounting economic and societal costs, and the crippling burden placed on health-care systems worldwide ${ }^{(1-3)}$. A number of environmental and lifestyle factors have been identified as important drivers of the global increase in overweight and obesity ${ }^{(4)}$. Moreover, one factor that has increased in tandem with the prevalence of obesity is the increase in out-of-home eating ${ }^{(5,6)}$. In Ireland, it is estimated that adults consume up to $24 \%$ of their total energy from foods and drinks that are purchased and eaten outside the home $^{(7)}$. Similarly, in the USA, adults consume on average $11 \%$ of their total energy intake from fast food and research shows that US adults who regularly eat out of home consume on average $837 \mathrm{~kJ}$ (200 kcal) extra daily ${ }^{(8)}$.

To address time deficits in increasingly busy lives, the demand for convenient food solutions has grown. The food-service sector has provided a variety of offerings to satisfy increasing convenience requirements and consideration has also been given to fulfilling enjoyment and value for money when eating out of home ${ }^{(9)}$. Nevertheless, research indicates that less consideration has been given to the nutritional profile of foods commonly consumed out of home ${ }^{(4,10)}$. Out-of-home eating is associated with increased risk of obesity, increase in body fat, higher intakes of saturated fat and energy, and lower intakes of fruit, vegetables and fibre ${ }^{(4,11)}$. In response to the growing 
prevalence of obesity and the adverse impact of out-ofhome eating, there is an urgent need to develop public health strategies that can positively influence food choice and improve population-level dietary patterns ${ }^{(12,13)}$.

Modifying food environments is an effective method for achieving behaviour change at a population level and the food-service industry can play an important role in promoting this ${ }^{(14)}$. Energy (calorie; i.e. kilocalories, $1 \mathrm{kcal}=4.184 \mathrm{~kJ})$ menu labelling has been identified as a population health strategy that can improve dietary behaviour outside of home by enabling people to make informed food choices ${ }^{(15,16)}$. Calorie labelling is an example of a nudge strategy whereby the food choice architecture of an environment is altered through the provision of information regarding the energy value of meals ${ }^{(17)}$. Without limiting their free choice, individuals may be nudged towards making healthier food choices, thus enabling them to control their energy consumption and body weight ${ }^{(18,19)}$. Calorie labelling can positively influence food choice as it raises awareness of energy intake, promotes informed food choices and results in an increased demand for lower-energy options ${ }^{(16)}$.

Calorie menu labelling has been introduced in a number of countries and regions, including on a mandatory basis in the USA, Australia and Canada and under voluntary agreements in the UK and the Republic of Ireland ${ }^{(20)}$. Research suggests that calorie labelling can positively influence consumers' sensitivity to energy when making food-purchasing decisions, which in one study resulted in a sustainable reduction $(6 \%)$ in the amount of energy consumers purchased over a 10 -month period ${ }^{(16)}$. Similar results were reported in an Australian study, with a 9\% decrease in the median energy value of meals purchased over a 20-month period $^{(21)}$. Research has also indicated that the introduction of calorie labelling at the point of purchase in chain restaurants was associated with a significant reduction in BMI (1.5\%) and risk of obesity (12\%) among consumers ${ }^{(22)}$.

In 2012, the Minister for Health called on all food-service businesses to voluntarily display calories under the 'Calorie Menu Labelling Scheme' as part of a multifaceted approach to reduce the burden of overweight and obesity in Ireland. An evaluation of the scheme conducted by the Food Safety Authority of Ireland (FSAI) in 2013 revealed that only $8 \%$ of businesses claimed to display calories. The key issue surrounding the low uptake centred on the lack of skills and training resources to facilitate accurate calorie calculation $^{(20,23)}$. In April 2014, in response to this report, the FSAI launched a free 'MenuCal' application, which was designed to enable food-service businesses to calculate calories on their menus. The results of the report are consistent with international research that has identified a number of barriers to calorie menu labelling, including lack of nutrition expertise, time, cost, inaccuracy concerns and customer dissatisfaction $^{(24)}$. The aim of the present study was to investigate Irish food-service business owners' uptake of and attitudes towards voluntary calorie menu labelling and to inform national and international policy makers on factors to consider to ensure successful implementation of calorie menu labelling.

\section{Methods}

\section{Study design}

A mixed-methods approach combining a national telephone survey, structured observation visits and semistructured interviews was employed. Combining both quantitative and qualitative methods allowed for a more thorough exploration of food-service businesses' uptake of and attitudes towards a voluntary government-led calorie menu labelling initiative in Ireland ${ }^{(25,26)}$. Qualitative research methods (semi-structured interviews) were used to further explore quantitative findings (national telephone survey).

A stratified random sample ( $n$ 1781) of all current foodservice businesses in Ireland (8750 food businesses, representing over 22000 outlets in total) was obtained by a private third-party data company. Of this, a study sample size of 1006 was used in the present study with a response rate of $60 \%$ ( $n$ 604).

The food-service businesses were stratified by business category: (i) café/coffee shop/deli; (ii) caterers; (iii) convenience stores; (iv) fast-food retail; (v) restaurants (including hotel restaurants); (vi) pubs; and (vii) service stations, and ranged in size from one single outlet to businesses with hundreds of outlets. Table 1 illustrates the number of businesses that completed the survey from each business category. A trained research team, which included nutritionists, a dietitian and research assistants, conducted the telephone surveys, observation visits and semi-structured interviews in a standardised manner.

\section{National telephone survey}

Businesses were randomly contacted from the stratified list and data collection covered all three provinces in Ireland in addition to three counties in Ulster (Donegal, Monaghan and Cavan). Both urban and rural settings were targeted and a wide variety of businesses serving different ethnic cuisines were contacted. All data obtained were anonymised. Only individuals with a decision-making role in the policies implemented within their food-service outlets were eligible to complete the survey. Both open and close-ended questions were included. Participants were asked the openended questions first to prevent participant priming and the surveys took approximately $10 \mathrm{~min}$ to complete. The survey focused on: (i) the structure of the food business, service provided, customer point of order, number of meals served; and (ii) the delivery/non-delivery of the calorie content (reasons for display/non-display, location of information, time of display, form of information, methods used to calculate calories and additional information provided).

To ensure systematic bias was not introduced, a pilot survey was conducted with a small representative sample 
Table 1 Overview of the number of food-service businesses that completed the telephone survey according to business category, Republic of Ireland, June 2015

\begin{tabular}{|c|c|c|c|c|c|c|}
\hline \multirow[b]{2}{*}{ Business category } & \multicolumn{2}{|c|}{ Total $(n$ 604) } & \multicolumn{2}{|c|}{ Chain* (n 82) } & \multicolumn{2}{|c|}{ Single outlet owner ( $n$ 522) } \\
\hline & $\%$ & $n$ & $\%$ & $n$ & $\%$ & $n$ \\
\hline Café/coffee shop/deli & $17 \cdot 9$ & 108 & $28 \cdot 0$ & 23 & $16 \cdot 3$ & 85 \\
\hline Caterer & $6 \cdot 0$ & 36 & 0.0 & 0 & 6.9 & 36 \\
\hline Convenience store & 11.3 & 68 & $18 \cdot 3$ & 15 & $10 \cdot 3$ & 53 \\
\hline Fast-food retail† & $12 \cdot 3$ & 74 & $23 \cdot 2$ & 19 & 10.5 & 55 \\
\hline Pub & 11.9 & 72 & 3.7 & 3 & $13 \cdot 2$ & 69 \\
\hline Restaurant/hotel & $32 \cdot 8$ & 199 & $18 \cdot 3$ & 15 & $35 \cdot 1$ & 184 \\
\hline Service station & $7 \cdot 8$ & 47 & 8.5 & 7 & $7 \cdot 7$ & 40 \\
\hline
\end{tabular}

${ }^{*}$ Chains are businesses that had more than one outlet.

†Fast-food retail includes fast-food restaurants and takeaways.

( $n$ 15). Data were analysed to ensure that the content was acceptable, to identify an excessive use of 'don't know' or neutral responses, and to ensure that the questionnaire length was acceptable. All interviewers were trained and the survey data were monitored by the study coordinator every $3 \mathrm{~d}$. Descriptive statistics were conducted using the statistical software package IBM SPSS Statistics version 21 for Windows and were assessed according to business category and display/non-display of calorie information. The findings from the survey are presented at the business level (i.e. all food-service businesses, including chains, are counted as a single business, irrespective of the number of outlets). In the case of chain outlets, interviewees where asked to clarify if all chain outlets implemented the same set-up with regards to calorie labelling. Furthermore, triangulation of data collection methods to include both qualitative and quantitative methods further minimised the risk of bias.

\section{Structured observation visits}

Based on findings from the telephone survey, structured observation visits were conducted to observe the visual application of calorie labelling. A total of eighty businesses were visited. To ensure selection bias was not introduced, all businesses that indicated in the telephone survey that they displayed calories ( $n$ 42), along with a random sample ( $n$ 38) of businesses that indicated they did not display calories, were visited. To ensure consistency among chain outlets, a number of chain outlets were visited in different locations, using random sampling. To ensure that the research team would be granted access, outlet managers were contacted via telephone to set up a suitable date. Each observation visit lasted approximately $15 \mathrm{~min}$ and foodservice businesses provided written informed consent. Descriptive statistical data were analysed using IBM SPSS Statistics version 21 for Windows and differences between observations were assessed according to food business category and display/non-display of calories.

\section{Semi-structured interviews}

Findings from the telephone survey informed the semistructured interviews. Purposive sampling was used to recruit participants who had a decision-making role in the policies and procedures implemented in the food-service business. Participants who completed the telephone survey were contacted once more by telephone and followed up by email. Participants included managing directors, owners, head chefs and franchisees across Cork, Dublin, Kerry and Galway. A total of thirteen face-to-face interviews were conducted. The interview focused on participants' perceptions and experiences, potential barriers and facilitators surrounding the implementation of calorie menu labelling. A semi-structured topic guide was developed to allow for comparisons of experiences and attitudes in relation to calorie menu labelling (see Appendices 1 and 2). The topic guides took an inductive approach and allowed for unique insights and perspectives to emerge. Respondent validation was ensured by means of debriefing at the end of the interview. The interviews were conducted in the participants' workplace and lasted approximately $40 \mathrm{~min}$ to $1 \mathrm{~h}$. Incentives were provided to ensure participation.

A framework approach was used for data analysis ${ }^{(27)}$. Data were managed through a process of summarisation, resulting in a robust and flexible matrix output, which allowed the research team to analyse data by case and theme. This approach is suitable when there are prespecified aims and objectives; however, familiarisation allows unexpected themes to emerge. Familiarisation involved the researchers immersing themselves in the raw data by listening to audio tapes, re-reading transcripts and observation notes, and noting recurring themes in an analytical memo. Thematic analysis was used to identify the main barriers and facilitators surrounding calorie menu labelling. This involved four researchers coding a selection of transcripts which were subject to inter-coder reliability as one of the researchers was not involved in data collection. Open coding facilitated an inductive approach and a coding framework was developed by discussing convergence and divergence of codes. Interviews were digitally recorded, transcribed and analysed using the qualitative data analysis software NVivo version 11 . Coded data were further abstracted and themes were arranged into charts to facilitate interpretation. 


\section{Results}

\section{National telephone survey}

The national telephone survey was completed by 604 food-service businesses (2308 food-service establishments when the number of outlets was considered for each business). In the case of chain outlets, this was generally a head office contact (e.g. managing director), who was asked to clarify if all chain outlets implemented the same set-up with regards to calorie labelling. Participation in the telephone survey varied according to business category (Table 1$)$. In the telephone survey, $7 \%(n$ 42) of the businesses indicted that they displayed calories. Of these, $26 \%$ ( $n$ 11) were restaurants/hotels, 19\% $(n 8)$ were convenience stores, $17 \%(n$ 7) were fast-food retailers, $17 \%(n$ 7) were cafés/coffee shops/delis, 9\% ( $n$ 4) were catering companies, 7\% ( $n$ 3) were service stations and $5 \%(n$ 2) were pubs. Of the food services that indicated they displayed calories, 38\% ( $n$ 16) were classified as a chain ( $n$ 1169) based on the number of outlets and 62\% ( $n$ 26) were classified as single-outlet owned businesses.

\section{Reasons for not displaying calories}

The profile of the food businesses (i.e. business category, size, meal types served, etc.) that did not display calories (93\%, $n$ 562) did not differ from that of the total sample population. The most common reasons reported by food-service businesses for not displaying calorie information were that it was time-consuming (33\%, $n$ 183), costly (26\%, $n$ 143), unnecessary (25\%, $n$ 140) and not mandatory $(16 \%, n 113)$. Concerns regarding the accuracy of the calories $(15 \%, n 91)$ and a lack of training (14\%, $n$ 84) were also reported. Food-service businesses were asked to indicate strategies that they believed could be used to encourage businesses to display calories. Training and advice from professionals was reported as the main factor $(38 \%, n$ 123) that would increase the implementation of calorie menu labelling. Other strategies included allocation of funding (19\%, $n$ 108) and the use of an easy method for calculating calorie content (17\%, $n$ 94).

\section{Reasons for displaying calories}

The food-service businesses that reported that they displayed calories were asked to indicate their reasons for doing so. Food services were able to choose more than one reason. A total of $62 \%$ ( $n$ 26) of the businesses displayed calories as they felt it was the right thing to do, $52 \%$ ( $n$ 22) believed that it helped promote healthy eating and $48 \%$ ( $n$ 20) indicted that it enabled consumers to make informed decisions. A proportion of the businesses (31\%, $n$ 13) indicated that they displayed calories as part of the national voluntary calorie menu labelling scheme and $17 \%(n 7)$ reported that they were doing so to improve their business.
Methods used to display calories

Of the food-service businesses that reported they displayed calories, differences were observed in how calories were calculated. Calories were calculated internally in $50 \%$ ( $n$ 21) of the food-service businesses and $26 \%$ ( $n$ 11) of businesses received calorie information from their franchisor. It was reported that to support in-house calculation of calorie information, food businesses predominantly $(52 \%, n$ 11) used electronic sources such as MenuCal, NutriCal, the electronic database 'Source' and the mobile application 'My Fitness Pal'. Other methods of in-house calculations included information provided by food suppliers, nutrition books and online references. In the food-service businesses that did not use in-house calculations to estimate calories, an external nutritionist/ dietitian calculated calories in $14 \%(n 6)$ of the businesses and nutrition analysis labs and information provided by food suppliers were used in 10\% ( $n$ 4) of the businesses.

Differences were observed regarding how food-service businesses displayed the calorie information. A total of $45 \%$ ( $n$ 19) of food businesses reported that they displayed calories on a per portion basis, 33\% ( $n$ 14) displayed calories on a per meal basis and $12 \%(n 5)$ reported using both these units. A further 5\% $(n 2)$ of businesses indicated that they displayed calories on a per $100 \mathrm{~g}$ basis and 5\% ( $n$ 2) indicated that they displayed calories on a per portion and per $100 \mathrm{~g}$ basis. Differences were also reported regarding the location of calorie information. Calorie information was displayed on a menu board in 33\% ( $n$ 14) of businesses, 31\% ( $n$ 13) displayed calories on a printed menu, $14 \%(n 6)$ displayed calories on a leaflet/table mat or through electronic sources and $8 \%$ ( $n$ 2) of businesses displayed calories on a chalkboard. Other locations included posters, customer request books, flip displays and quick response codes on mobile phone applications.

\section{Observation visits}

Observation visits were conducted as a means of validating quantitative data collected by the national telephone survey. Table 2 provides an overview of the observation visits completed. Findings from all thirty-eight businesses visited that claimed not to display calories corresponded with quantitative data obtained. Of the forty-two businesses that indicated in the telephone survey that they displayed calories, $10 \%$ ( $n$ 4) did not display calories during the observation visits. Of the businesses that did display calories ( $n$ 38), 92\% ( $n$ 35) did so at the point of choice (i.e. on menus or menu boards). Differences were observed among food-service chains regarding the format in which calories were displayed. For example, for one large chain that claimed in the telephone survey to display calories, only one of the eleven outlets visited provided calorie information and it was displayed as a pocket-sized leaflet on the deli counter and not at the point of choice. For one large fast-food chain, of the four outlets that were 
Table 2 Overview of the number of observation visits of food-service businesses completed according to number of outlets, business category and location, Republic of Ireland, June 2015

\begin{tabular}{|c|c|c|c|c|c|c|c|c|}
\hline & \multicolumn{2}{|c|}{ Total $(n 80)$} & \multicolumn{2}{|c|}{$1-20$ outlets ( $n$ 16) } & \multicolumn{2}{|c|}{$21-60$ outlets $(n 19)$} & \multicolumn{2}{|c|}{$>60$ outlets $(n 45)$} \\
\hline & $\%$ & $n$ & $\%$ & $n$ & $\%$ & $n$ & $\%$ & $n$ \\
\hline \multicolumn{9}{|l|}{ Business category } \\
\hline Café/coffee shop/deli & 38.8 & 31 & 37.5 & 6 & $57 \cdot 9$ & 11 & $31 \cdot 1$ & 14 \\
\hline Convenience store & 22.5 & 18 & $6 \cdot 3$ & 1 & 0.0 & 0 & 37.8 & 17 \\
\hline Fast-food retail & $30 \cdot 0$ & 24 & $25 \cdot 0$ & 4 & $42 \cdot 1$ & 8 & $26 \cdot 7$ & 12 \\
\hline Restaurant/hotel & $6 \cdot 2$ & 5 & $31 \cdot 2$ & 5 & 0.0 & 0 & 0.0 & 0 \\
\hline Service station & $2 \cdot 5$ & 2 & 0.0 & 0 & 0.0 & 0 & $4 \cdot 4$ & 2 \\
\hline \multicolumn{9}{|l|}{ Location } \\
\hline Cork & 27.5 & 22 & $12 \cdot 5$ & 2 & 31.6 & 6 & 31.2 & 14 \\
\hline Dublin & $50 \cdot 0$ & 40 & $43 \cdot 8$ & 7 & $47 \cdot 3$ & 9 & $53 \cdot 3$ & 24 \\
\hline Galway & 2.5 & 2 & 0.0 & 0 & $5 \cdot 3$ & 1 & $2 \cdot 2$ & 1 \\
\hline Kerry & $8 \cdot 8$ & 7 & $6 \cdot 2$ & 1 & $5 \cdot 3$ & 1 & 11.1 & 5 \\
\hline Kildare & 1.2 & 1 & $6 \cdot 2$ & 1 & 0.0 & 0 & 0.8 & 0 \\
\hline Limerick & 10.0 & 8 & $31 \cdot 3$ & 5 & 10.5 & 2 & $2 \cdot 2$ & 1 \\
\hline
\end{tabular}

visited, two outlets had calories displayed at the point of choice while two outlets displayed calories on a poster. For another large fast-food chain, all three outlets visited displayed calories at the point of choice. However, it is important to note that for two large retailers, calorie menu labelling had been recently introduced as a policy and stores were actively implementing menu labelling at the time of the survey.

Furthermore, it was observed that of the food-service businesses that displayed calorie information, only $32 \%$ ( $n$ 12) were also displaying calorie requirements (recommended daily calorie intakes). Calorie requirements were mostly displayed on posters ( $n$ 6), at the point of choice or on tablemats ( $n$ 4). One business displayed calorie requirements on posters and tablemats, and one business displayed calorie requirements on its website.

\section{Semi-structured interviews}

Of the food-service businesses that participated in the interviews, two were cafés/coffee shops/delis, six were fast-food retailers, four were restaurants/hotels and one was a convenience store. Each of the interviewees had decision-making responsibilities within their business and the sample included food-service businesses that did and did not display calorie information. Three major themes emerged: uncertainty, impact on business and consumer nutrition knowledge. These themes are discussed as either barriers to or facilitators of implementing calorie menu labelling.

\section{Theme: Uncertainty}

Participants from all food-service business categories expressed apprehension regarding the implementation of calorie menu labelling in their businesses. Concerns regarding the accuracy of calorie information were central to this apprehension. The main concern among singleoutlet fast-food businesses was the difficulty of adhering to portion control in a fast-paced environment. Those displaying calories highlighted that discrepancies in serving size and calorie information obtained from suppliers hindered the implementation of accurate calorie information. Further issues of concern included cost implications and time commitments. Calorie menu labelling implementation was identified as a resource-intensive, costly and time-consuming process, particularly by businesses with non-standardised menus. Single-outlet owners and participants from small chain businesses that did not display calories identified their financial inability to outsource (hire an external nutritionist) as a barrier to implementation. Single-outlet business owners who displayed calories and did not outsource identified the most expensive aspect to be the purchasing of adequate nutritional analysis software and the most time-consuming step to be recipe standardisation. Conversely, participants of large chain restaurants displaying calories identified their financial ability to outsource for nutritional analysis as a facilitating factor for implementation. Concerns were also expressed regarding food-service business owners' lack of trust regarding the policing of the proposed legislation. Participants who were not displaying calories expressed concerns regarding the accuracy of calorie information, which created a sense of mistrust in the food-service industry. This mistrust was identified as a barrier to implementation. Some participants raised concerns over compliance with the proposed legislation and felt that not all businesses would provide accurate calorie information, especially if calories were calculated internally. There was general agreement that rigorous enforcement and regulation by health authorities would be a key to ensuring standardisation of calorie menu labelling.

Verbatim examples are included in Table 3.

\section{Theme: Impact on business}

All participants indicated that the implementation of calorie menu labelling would have an impact on their business. Those displaying calories had a desire to improve company image and boost customer loyalty and perceived displaying calories as a means of achieving this. 
Table 3 Theme of 'uncertainty' and verbatim examples from semi-structured interviews exploring food-service businesses' uptake of and attitudes towards a voluntary government-led menu energy (calorie) labelling initiative, Republic of Ireland, June 2015

Verbatim examples
1. Accuracy
'You've to start weighing how much sauce you're actually putting on a burger but then that's not
accurate either because that's how much I put and then someone else may put a different amount
and then it's even based on how busy you are. When you're busier you just kind of do it, you're not
stopping and worrying "oh this might be a tad too much, a tad too little".' (Owner, independent fast-
food outlet, not displaying calories)
'One of the things that we did do was we empowered a lot of our franchisees with tools to make sure the
quantity of product that was going on the pizza was consistent. We developed a cup system where
there are individual measurements inside the cup. So for a 7-inch pizza, you would go to the first line
and for a 9-inch you would go to the second line.' (Managing director, chain fast food, displaying
calories)
'I suppose for us, we don't have to go looking for all this information you know it's there for us; we get
emails, we get all the point-of-sales material for in-store, so it's made quite simple for a franchisee
here.' (Franchisee, chain fast food, displaying calories)
'It is almost impossible, first of all, for someone like me, who changes the menu almost on a daily basis.
Counting calories is a very difficult thing when you don't have a standardised menu ... I would have to
calculate the calories every single day and I have not got time for that, could I afford to outsource?
No! So, basically it is impossible.' (Owner/head chef, independent restaurant, not displaying calories)
'I don't think businesses are going to be entirely 100\% scrupulous about doing it. I think if there is not an
easy way of doing it then businesses will end up guessing.' (Owner, independent cafe, not displaying
calories)
'What I don't believe in is if you go up to some of our competitors there, some of the big boys, they have
their calorie count already printed on their cartons but the way they have done it is kind of sly if you
like. They're showing half the calories for half the weight if you know what I mean. They're trying to
disguise the fact on some of it. I don't think that is the way to go.' (Owner, independent fast food, not
displaying calories)

Participants believed that displaying calories would help them to portray their businesses as dynamic, thus they were supportive of implementation and were prepared to overcome perceived barriers (e.g. stabilising portion control to permit accurate calorie information); while those not displaying calories highlighted hesitation to do so over concerns regarding the negative impact on the dining experience and portrayal of product. Logistical concerns were expressed regarding a lack of menu space to display calories and its impact on aesthetics. Single-outlet restaurant owners not displaying calories felt that calorie labelling would clutter the menu and that the large quantity of information would overwhelm customers. However, among businesses displaying calories, the incorporation of a marketing element was perceived as a valuable facilitating factor for implementation. In addition, many participants considered their customers were consciously aware of the dietary quality of food they chose to consume and felt that this impeded implementation. There was a perceived low customer demand for calorie information among fast-food establishment owners and they believed that most customers formed food preferences prior to entering their premises. Furthermore, many single-outlet restaurant owners felt that because they catered for occasion dining, the customers in this instance were not too concerned about eating particularly healthy foods. Apprehension surrounding the negative portrayal of menu items was also perceived as a barrier for implementation by participants not displaying calorie information. It was anticipated that items would be viewed as unhealthy by customers if calories were displayed, which would have a negative effect on business. Reshaping menus to reduce calorie content was reported to have a positive impact on product portrayal by those displaying calories. In addition, this was perceived to be a critical facilitating factor in overcoming negative product portrayal by those not displaying calories. The most likely way of achieving this was by reformulating recipes, reducing portion sizes and adding additional healthy options. Large chain establishments reported using marketing tools to enable them to portray products in a way that was not detrimental to business. Some participants, particularly single-outlet fastfood establishment owners, felt a sense of powerlessness when it came to changing menus as they anticipated customer resistance to change, specifically regarding portion size.

Verbatim examples of this theme are included in Table 4 .

\section{Theme: Consumer nutrition knowledge}

While some participants perceived that their customers were broadly aware of the dietary quality of their food preferences, a lack of consumer nutrition knowledge was identified as a potential barrier to implementation of calorie menu labelling. It was anticipated that consumers may misinterpret calories, causing them to opt for lower-calorie options, rather than the more nutritious and healthier option. It was feared that consumers may use calories as a measurement of 'value for money' (i.e. more calories translate into value for money). Educating the nation on healthy eating was perceived as a crucial facilitating factor in implementing calorie menu labelling. This was believed 
Table 4 Theme of 'impact on business' and verbatim examples from semi-structured interviews exploring food-service businesses' uptake of and attitudes towards a voluntary government-led menu energy (calorie) labelling initiative, Republic of Ireland, June 2015

\begin{tabular}{|c|c|}
\hline & Verbatim examples \\
\hline 1. Company image & $\begin{array}{l}\text { 'We heard they were coming in, so we said, "let's get onto it and do it straight away, if we are going to have to do it, } \\
\text { we might as well do it now.' ... I suppose it was partly for the publicity end of it.' (Owner, independent restaurant, } \\
\text { displaying calories) } \\
\text { 'We're trying to be ahead of the curve and we're anticipating legislation which would require us to do it anyway.' } \\
\text { (Head chef, independent hotel restaurant, displaying calories) }\end{array}$ \\
\hline $\begin{array}{l}\text { 2. Boost customer } \\
\text { loyalty }\end{array}$ & $\begin{array}{l}\text { 'By declaring calories, you're being open and straight up with the customer; they will have more confidence in you ... } \\
\text { they will have more confidence going to your company rather than someone else's company.' (Managing director, } \\
\text { chain fast food, displaying calories) } \\
\text { 'I would look at it to improve my day trade. If we could offer a service of a lower-calorie menu by day, it might } \\
\text { encourage more ... I believe that it could be positive in generating extra customers.' (Owner, chain fast food, not } \\
\text { displaying calories) }\end{array}$ \\
\hline $\begin{array}{l}\text { 3. Impact on dining } \\
\text { experience }\end{array}$ & $\begin{array}{l}\text { 'To put the calories on the menu you serve to every customer is ridiculous! It looks silly. This is a fine dining } \\
\text { restaurant. You know, we charge a lot of money here, so it would kind of bring the menu down. It would make it } \\
\text { look less "high end". People don't come here to watch what they eat. They come here to enjoy themselves and it is } \\
\text { more for the taste and the flavours.' (Owner/head chef, independent restaurant, not displaying calories) } \\
\text { 'When you come here for afternoon tea, it's a treat, you know, it's a real treat. You're going to come, you're going to } \\
\text { have your lovely tea, you're going to have a glass of champagne and the lovely pastries and scones and so on } \\
\text { and so forth, so do you really want to know about calories?' (Head chef, independent hotel restaurant, displaying } \\
\text { calories) }\end{array}$ \\
\hline 4. Portrayal of product & $\begin{array}{l}\text { 'It could be bad for trade ... regular customers that you have been getting all the time, if they find out all of a sudden } \\
\text { about the calorie content, their mind may just tell them "no"! We'd just have to start coming up with recipes that are } \\
\text { lower in calories.' (Owner, chain fast food, not displaying calories) } \\
\text { 'Our sandwich has } 1000 \text { calories in it and that is the last thing customers wanted, as soon as they seen that it was } \\
\text { like "wow, didn't realise it was that high". So we did reduce certain items in a couple of dishes because when the } \\
\text { calories came out, they came out so high.' (Owner, independent restaurant, displaying calories) }\end{array}$ \\
\hline
\end{tabular}

Table 5 Theme of 'consumer nutrition knowledge' and verbatim examples from semi-structured interviews exploring food-service businesses' uptake of and attitudes towards a voluntary government-led menu energy (calorie) labelling initiative, Republic of Ireland, June 2015

\begin{tabular}{ll}
\hline & Verbatim examples \\
\hline $\begin{array}{c}\text { 1. Nutrition } \\
\text { education }\end{array}$ & 'People don't have a breeze when it comes to nutrition. ... The government need to educate people on what proper nutrition \\
is ... like if you ask the general Joe Soap, "how many calories are in the average dinner?", you know they won't have a \\
clue. If people are not educated to make good food choices, how is putting a number beside each dish going to change \\
that? It is not the way forward. It needs to come from an education background not forcing people to look at these numbers \\
all the time.' (Owner/head chef, independent restaurant, not displaying calories) \\
'We have loads of young people coming in and they are all looking to spend about five or six euro on lunch and if they see \\
that a chocolate muffin is the same calorific value as a bowl of soup, they don't know that it is not the same nutritional value \\
so they will just have a chocolate muffin and they say, "yeah it's only 280 calories". They would end up eating something \\
that has much worse nutritional value but the same amount of calories.' (Owner, independent cafe, not displaying calories)
\end{tabular}

to be the responsibility of the government via national health promotion agencies such as Safefood and the FSAI.

Verbatim examples of this theme are included in Table 5.

\section{Food-service businesses' recommendations}

Among all food-service business categories, several factors were identified as being central to enabling successful implementation of calorie menu labelling. These included guidance and advice, financial support, easier methods for calorie calculation and providing comprehensive nutrition information. Participants believed that these factors would alleviate barriers to implementation, specifically regarding cost, time and accuracy. Verbatim examples are included in Table 6.

Training and guidance. Some participants expressed interest in attending seminars/conferences where they could receive guidance and advice regarding the logistics of how to go about implementing calorie menu labelling, which would appease concerns regarding accuracy. In addition, participants expressed a need to create group cohesiveness regarding communication of calorie labelling and advised that all relevant parties involved in the proposed legislation should partake in open communication and work together in the implementation of calorie menu labelling.

Financial support. All businesses expressed the need for calorie menu labelling to be cost neutral for businesses. Single outlet owners felt there was a need for financial support in the form of grants or tax incentives/breaks. Among those unfamiliar with the FSAI MenuCal application, it was suggested that the provision of a free caloriecounting service would be beneficial in eliminating the financial burden of hiring an external source or purchasing software to calculate calories.

Easier method of calorie calculation. Participants who had no experience in using the FSAI MenuCal application 
Table 6 Food-service businesses' recommendations and verbatim examples from semi-structured interviews exploring their uptake of and attitudes towards a voluntary government-led menu energy (calorie) labelling initiative, Republic of Ireland, June 2015

Verbatim examples

1. Training, guidance and advice

2. Financial support

3. Easier method of calorie calculation

4. Comprehensive nutrition information
'I would like for the government to consult with us ... I would like it to be as thorough as possible with honest and open communication.' (Head chef, independent hotel restaurant, displaying calories)

'It is an expense and it could end up being very expensive, I think there should be some sort of grant. So if there was something like you register and you get $\mathrm{X}$ amount or even the first year off, it would encourage people to do it.' (Owner, independent restaurant, not displaying calories)

'If there was a program there for us to use where we just punch what is going into that dish and it will calculate the calories, we will go with that. If it is an approved system, it would be great. That way they can't come back and say "oh, your chef is wrong", because we used their approved system.' (Owner, independent restaurant, not displaying calories)

'They have to make it as user-friendly as possible, they have to sit themselves down in front of the computer and say, "right, l'm a chef here; I have like five minutes to do this thing".' (Head chef, independent hotel restaurant, not displaying calories)

'Traffic lights would probably be something quick and easy that customers would see, you know and rather than going through and counting up the calories themselves they would have a high-calorie, medium-calorie, low-calorie quick reference menu.' (Franchisee, chain fast food, displaying calories). anticipated that it would be beneficial in alleviating cost concerns and that the use of department-approved software would ease accuracy concerns, providing it was user-friendly and time-efficient. However, participants who had attempted to use MenuCal found that it was labour-intensive to use and expressed concerns regarding its accuracy. Concerns were also raised over the inability to find products in the system, the level of discrepancies between product types, and the laborious necessity to replicate data entered previously.

Education programme to coincide with the implementation of calorie menu labelling. As participants perceived a lack of consumer nutrition knowledge as a barrier to implementation, they highlighted the need for an education piece to be implemented along with the rollout of calorie menu labelling to ensure that customers understood the application of calories to food menus.

Comprehensive nutrition information. Most establishments that were displaying calorie information displayed additional nutrition information alongside it. Among those displaying this information, it was felt that customers sought more than just calorie information alone. Many participants from establishments not displaying calories also believed that there was need to provide additional nutrition information to customers in relation to other nutrients like saturated fat, sugar and salt. It was suggested that a menu traffic light coding system may be more beneficial and more easily understood by customers than calories alone as it allows customers to quickly assess the relative healthiness of menu items using a simple colourcoded system.

\section{Discussion}

The present study aimed to investigate the uptake of and attitudes towards a government-led, voluntary calorie menu labelling initiative in Ireland among food-service businesses. The study also sought to inform public health policy makers regarding further necessary actions to facilitate successful calorie labelling implementation. Poor levels of compliance of calorie labelling on menus were observed, with a higher proportion of chain food-service businesses displaying calories on their menus when compared with single-outlet owned businesses. Furthermore, the structured observation visits demonstrated that a proportion of food-service businesses that indicated during the telephone survey they do display calories did not have calorie information on display during the visits, thus it may be likely that even fewer food-service businesses than reported have embraced the voluntary initiative. The semi-structured interviews established barriers to and facilitators of implementing calorie labelling and three principal themes emerged: uncertainty, impact on business and consumer nutrition knowledge. Contextual factors influenced the implementation of calorie labelling.

Food-service businesses not displaying calories were apprehensive to do so and expressed concerns regarding the potential negative impact on the dining experience and the portrayal of the food product/meal. Participants anticipated that calorie labelling might lead to menu items being perceived as unhealthy by customers, which could lead to a decline in sales. Similar concerns have been reported previously ${ }^{(28)}$. However, mandatory display of calories may stimulate action from food-service businesses as it may create an incentive to reformulate and improve the nutrition profile of menu items. Participants also expressed concerns regarding the accuracy of calorie information and outlined difficulties in standardising portion sizes. Further concerns regarding the cost implications, time commitments, mistrust in the food industry and poor consumer nutrition knowledge were expressed by the participants. Apprehension regarding each of these concerns served as a barrier to calorie menu labelling and impeded the uptake of the initiative. These findings are consistent with previous research, which also identified time and cost constraints and concerns regarding the inaccuracies in calorie information due the absence of a standardised menu as barriers to implementing calorie labelling ${ }^{(29)}$. 
Conversely, food-service businesses that were displaying calorie information had a desire to improve company image and boost customer loyalty and perceived calorie menu labelling as a means of achieving this desire. This desire was found to facilitate the implementation of calorie menu labelling and is consistent with previous research which suggests that displaying calories on menus may beneficial to food-service businesses' revenue as calorie labelling can be used as a marketing tool to attract customers $^{(30)}$. Professional training and advice, financial support, user-friendly methods of calorie calculation and the provision of comprehensive nutrition information were perceived as facilitating factors, which would increase compliance with calorie menu labelling. Some of these findings are consistent with the FSAI report, which highlighted that inadequate access to training resources served as a significant barrier to the implementation of calorie menu labelling ${ }^{(20)}$

A sense of mistrust of the food industry among food business owners, coupled with the poor rate of compliance, suggests that there may be a lack of support from the food-service industry in the implementation of calorie menu labelling. This demonstrates the need for a collaborative approach between policy makers, food-service business owners and academics to increase compliance. A previous study revealed that good communication with restaurant owners is key to establishing trust, which in turn can help alleviate concerns and overcome the barriers associated with implementing menu posting ${ }^{(31)}$. It is imperative that prior to implementation of calorie labelling, policy makers provide regular training sessions for food-service business owners to equip them with the knowledge and skills necessary to implement calorie labelling within their businesses. Nutrition professionals should deliver these training sessions and outline the time and cost resources that are required for successful calorie menu labelling. Furthermore, policy makers need to consider the benefits of offering a financial incentive such as a grant or a tax break, particularly to single-outlet owned businesses. It is likely that such an incentive would increase compliance rates. Ultimately, cooperation from food-service businesses is key to successful implementation of a calorie menu labelling initiative. Moreover, businesses have the potential to enhance implementation by providing valuable insights into the needs of their customer base.

Concerns expressed among food-service business owners regarding the potential for inaccuracies in the calorie information demonstrate the need for independent regulation and continuous monitoring to check compliance and to ensure that a standardised and transparent approach to calorie menu labelling is employed across all food-service businesses. To address concerns regarding a lack of consumer nutrition knowledge, structured national education campaigns should be rolled out in parallel with the implementation of calorie menu labelling to increase awareness among the public. Furthermore, policy makers should consider the implementation of a comprehensive labelling system that combines calorie labelling, a nutritional breakdown of food items (i.e. fat, saturated fat, sugar and salt) and traffic light coding. This can provide consumers with detailed nutrition information regarding their food choices in a timely manner (i.e. at a glance). In a complex workplace dietary intervention, a traffic light coding system that also displayed the number of calories per meal/food item in a workplace canteen was associated with significant improvements in employees' diet quality, nutrition knowledge and obesity levels over a 9-month period $^{(32)}$.

The present study has a number of strengths. Data were collected from a representative sample of Irish foodservice business using a mixed-methods approach. The qualitative phase was built directly on the results of the quantitative phase (quantitative data obtained during the telephone survey informed the observation visits and the semi-structured interviews). This both facilitated a comprehensive exploration of the uptake of calorie menu labelling in Ireland and also validated the data by examining concordance between surveys and observation visits/interviews. Furthermore, the internal validity of the qualitative data was ensured through regular debriefing discussions. Efforts were made to remain as objective as possible by researchers conducting interviews with participants that they had no previous contact with (i.e. during the telephone survey). In addition, piloting of study methods ensured that high-quality data were obtained. The limitations of the study should also be considered. It is important to note that for some chain businesses, calorie posting had been recently introduced as a policy and individual chain stores were actively rolling out calorie labelling at the time the present survey was conducted. This may have resulted in over-reporting of compliance rates. Similarly, the food-service business owners received notice of when the observation visits were due to take place, which may have also resulted in over-reporting of compliance rates. Finally, the inclusion of respondent validation, by means of debriefing in the semi-structured interviews, may have been useful as participants' interpretation of emerging results can help further refine findings and strengthen recommendations.

\section{Conclusion}

While menu calorie labelling is one important low-risk strategy within the national plan to combat obesity in Ireland, it is important to recognise that no single obesity prevention strategy is likely to have a significant impact on an aggregated level. Calorie labelling should be implemented as part of a large-scale systemic programme of multiple obesity prevention strategies. To facilitate this and 
improve levels of compliance with calorie menu labelling, a collaborative approach between policy makers, academics and food-service business owners is needed to facilitate implementation. This approach should incorporate providing food-service business owners with guidance, support and practical assistance, along with a reasonable legislative structure and a standardised monitoring system.

\section{Acknowledgements}

Financial support: This work was supported by the School of Public Health, University College Cork, Ireland and funded by the Department of Health, Ireland. The Department of Health had no role in the design, analysis or writing of this article. Conflict of interest: The authors declare that there are no conflicts of interest. Authorship: All authors contributed to this work. L.G., F.G., M.M. and I.J.P. worked on the study design and methods. S.F. and L.G. were responsible for data analysis. S.F. and L.G. wrote the paper and all authors reviewed the manuscript. Ethics of human subject participation: This study was conducted according to the guidelines laid down in the Declaration of Helsinki and all procedures involving human subjects were approved by the Clinical Research Ethics Committee of the Cork Teaching Hospitals in Ireland. Written informed consent was obtained from all subjects.

\section{References}

1. World Health Organization (2000) Obesity: Preventing and Managing the Global Epidemic. Report of a WHO Consultation. WHO Technical Report Series no. 894. Geneva: WHO.

2. World Health Organization (2008) 2008-2013 Action Plan for the Global Strategy for the Prevention and Control of Noncommunicable Diseases. Geneva: WHO.

3. Roberto CA, Swinburn B, Hawkes C et al. (2015) Patchy progress on obesity prevention: emerging examples, entrenched barriers, and new thinking. Lancet 385, 2400-2409.

4. Lachat C, Nago E, Verstraeten R et al. (2012) Eating out of home and its association with dietary intake: a systematic review of the evidence. Obes Rev 13, 329-346.

5. Chaput JP, Klingenberg L, Astrup A et al. (2011) Modern sedentary activities promote overconsumption of food in our current obesogenic environment. Obes Rev 12, e12-e20.

6. Egger G \& Swinburn B (2011) Planet Obesity: How We're Eating Ourselves and the Planet to Death. Crows Nest, NSW: Allen \& Unwin.

7. Irish Universities Nutrition Alliance (2011) National Adult Nutrition Survey (NANS): Summary Report. https://irp-cdn. multiscreensite.com/46a7ad27/files/uploaded/The\%20National \%20Adult\%20Nutrition\%20Survey\%20Summary\%20Report\% 20March\%202011.pdf (accessed July 2018).

8. Nguyen BT \& Powell LM (2014) The impact of restaurant consumption among US adults: effects on energy and nutrient intakes. Public Health Nutr 17, 2445-2452.

9. Kaya IH (2016) Motivation factors of consumers' food choice. Food Nutr Sci 7, 149-154.
10. Osman I, Osman S, Mokhtar I et al. (2014) Family food consumption: desire towards convenient food products. Procedia Soc Behav Sci 121, Suppl. C, 223-231.

11. Nago ES, Lachat CK, Dossa RA et al. (2014) Association of out-of-home eating with anthropometric changes: a systematic review of prospective studies. Crit Rev Food Sci Nutr 54, 1103-1116.

12. Raine KD (2010) Addressing poor nutrition to promote heart health: moving upstream. Can J Cardiol 26, Suppl. C, 21c-4c.

13. Capacci S, Mazzocchi M, Shankar B et al. (2012) Policies to promote healthy eating in Europe: a structured review of policies and their effectiveness. Nutr Rev 70, 188-200.

14. Kahneman D (2011) Thinking, Fast and Slow. New York: Farrar, Straus and Giroux.

15. Nikolaou CK, Lean ME \& Hankey CR (2014) Calorielabelling in catering outlets: acceptability and impacts on food sales. Prev Med 67, 160-165.

16. Bollinger B, Leslie P \& Sorensen A (2011) Calorie posting in chain restaurants. Am Econ J Econ Policy 3, 91-128.

17. Marteau TM, Ogilvie D, Roland M et al. (2011) Judging nudging: can nudging improve population health? BMJ $\mathbf{3 4 2}$, d228.

18. Flynn MA (2015) Empowering people to be healthier: public health nutrition through the Ottawa Charter. Proc Nutr Soc 74, 303-312.

19. Thaler RH SC (2008) Nudge: Improving Decisions about Health Wealth and Happiness. New Haven, CT: Yale University Press.

20. Food Safety Authority of Ireland (2012) Calories on Menus in Ireland: Report on a National Consultation. Dublin: FSAI; available at http://www.fsai.ie/WorkArea/Download Asset.aspx?id=11419

21. NSW Government Food Authority (2013) Evaluation of Kilojoule Menu Labelling. Newington, NSW: NSW Food Authority.

22. Restrepo BJ (2017) Calorie labeling in chain restaurants and body weight: evidence from New York. Health Econ 26, 1191-1209.

23. Logue D, Kennelly J, Keaveney E et al. (2013) Calorie menu labelling in Ireland: a survey of food service businesses. Proc Nutr Soc 72, E167.

24. Thomas E (2016) Food for thought: obstacles to menu labelling in restaurants and cafeterias. Public Health Nutr 19, 2185-2189.

25. Mason J (2002) Qualitative Researching. London: SAGE Publications Ltd.

26. Gillham B (2008) Developing a Questionnaire, 2nd ed. London: A\&C Black.

27. Ritchie J, Lewis J, Nicholls CM et al. (2013) Qualitative Research Practice: A Guide for Social Science Students and Researchers. London: SAGE Publications Ltd.

28. Yamamoto JA, Yamamoto JB, Yamamoto BE et al. (2005) Adolescent fast food and restaurant ordering behavior with and without calorie and fat content menu information. J Adolesc Health 37, 397-402.

29. Gittelsohn J, Lee-Kwan SH \& Batorsky B (2013) Communitybased interventions in prepared-food sources: a systematic review. Prev Chronic Dis 10, E180.

30. Zick A, Wake Y \& Reeves S (2010) Nutrition labelling in restaurants: a UK-based case study. Nutr Food Sci $\mathbf{4 0}$, $557-565$.

31. Lee-Kwan SH, Goedkoop S, Yong R et al. (2013) Development and implementation of the Baltimore healthy carryouts feasibility trial: process evaluation results. BMC Public Health 13, 638.

32. Geaney F, Kelly C, Di Marrazzo JS et al. (2016) The effect of complex workplace dietary interventions on employees' dietary intakes, nutrition knowledge and health status: a cluster controlled trial. Prev Med 89, 76-83. 


\section{Appendix 1}

Topic guide for food-service businesses displaying calorie information

\section{TOPIC GUIDE FOR MANAGERS WHO ARE DISPLAYING CALORIES}

Firstly, I would like to thank you for taking the time to talk to me. My name is ... and I am a research assistant with the Department of Epidemiology and Public Health. I would like to briefly explain the rationale for the interview and, if you are happy to continue with the interview, I will ask you to sign a consent form before we commence the interview.

Rationale: The aim of this research is to investigate the uptake of voluntary calorie posting from a representative sample of food-service businesses in Ireland, to understand the underlying barriers and facilitators in the uptake of calorie labelling and to appreciate the personal opinions and experiences of food-service businesses that apply calorie labelling and inform any further action.

Duration of interview: The interview will take approx. $1 \mathrm{~h}$ and I would just like to check a few details before we get started.

- Would you mind if I record the interview? Anything we discuss will be confidential and your identity will remain anonymous on any reports or publications. Finally, you can stop the interview at any point, if you wish. Do you have any questions before we get started?

- Go through the consent form, sign and give copy.

Before we start the recording, may I ask you to confirm your position within the company and how long you bave been working in this role?

When you start recording, outline the following:

This is interview one recorded on (Date/Time)

Opening question: Firstly, I would like to get an understanding of your views on calorie labelling on menus? What is your opinion of calorie labelling on menus (do you agree or disagree with the concept?)

If calorie information is displayed on menu items, please ask the following questions:

\section{A) Motivation behind implementation of calorie labelling}

1) What motivated you/your company to introduce calorie information on your menu items?

- Who was involved in this decision? Was it solely your decision or a group decision?

- Who did you/the company seek advice from?

- How long did you/the company think about implementing before taking action?
2) When making this decision, what did you/your company consider being the potential benefits of introducing calorie labelling? What did you consider to be the potential risks?

- Business process, staff and consumer perspectives

- What did you worry about when making the decision to implement?

\section{B) Logistics of calorie labelling}

Now I would like to move on to talking about your/your company's experience around introducing calorie information on menu (having made the decision to do same)

1) What steps were taken to operationalise the posting of calorie information?

- Who was tasked with overseeing this project? Why was this person/people selected?

2) Were information sources used when creating the calorie labels: Why were these information sources used? Which were useful? Which would you/your company use again? Probes (if needed):

1. Was a nutritionist hired to help calorie profile each food? If yes, how was this person identified? Why choose this route to implement calorie labelling?

2. Did you or any other staff get training on how to calorie profile meals? If yes, why was it decided to get this training? Who provided this? What was the focus of this training and was it valuable? If not, why not?

3. Did you/the company seek specific advice from experts (unpaid)/others who had already introduced such information? What type of information and why did you/the company go to these sources? Was it useful?

4. Did you/the company use any online tools/technology to help in the calculation of calories? If so, what where they? Are you aware of the FSAI MenuCal? Have you/any other staff member used this? What did you/other staff think of it? 3) When introducing the information were specific dishes selected to trial the approach or were all dishes calorie profiled at the same time? Why was this approach taken?

- Was the calorie information applied to all foods and drinks on the menu in the same manner?

- Did you/the company encounter any difficulties when applying calories to different menu options, e.g. specials, made-to-order items?

4) How long did it take to create this calorie information? Could it have been done more quickly? Why?

- Did it impact on your current recipes and menus? Did it affect them? Was it necessary to standardise and document recipes prior to applying calorie labelling? Was this possible to do?

5) What costs were involved in implementing calorie labelling?

- Approximately how much did it cost the business overall?

- What were the sources of this cost (and relative contribution of each cost source)?

- Will there be ongoing costs? 
- Has displaying calories had any effect on your profit margins within the business?

6) As a result of providing this information to your customers have any of the following changed: (i) practices in the kitchen and in the ordering of food; (ii) the information required from suppliers; (iii) the range and types of food offered to your customers?

- Why were these changes necessary?

- Will any more changes be made to your practices and your menu as a result of having displayed calorie information? Why?

7) How confident are you/the company in the accuracy of the calorie information provided?

- What procedures are now in place to update calories on new/amended menu items? Who is responsible for this?

C) Attitude towards and perception of calorie labelling 1) Looking back, to what extent did the risks/benefits (pros and cons) envisaged in making these materialise (from a business process, staff and consumer perspective)?

- Why do you think this was the case?

- Did you encounter any unexpected benefits/drawbacks from implementation?

2) How did your customers react to the calorie labelling?

- Do you think your consumers read/understand this information? Does it influence their food choice? How? Would some rather it not be displayed?

3) Do you think food-service businesses should provide more than just calorie information to consumers?

- Do you think there is need to display 'daily calorie needs' or other nutritional information in addition to calories? Why? Where should this information be displayed? What do you think the benefits/drawbacks of this are?

4) Are you familiar with traffic light displays as a means of displaying additional nutrient information like saturated fats, sugars, salt of menu items?

- Do you think this would be beneficial to consumers?

- Do you think this type of display would be understood by consumers/influence their choice?

5) If you were commencing the process of calorie profiling again, what would you do differently?

- Why?

- What were the main challenges?

- What facilitated the process?

6) If giving advice to a friend in the food-service business who wanted to implement calorie labelling, what would you suggest they do?

- Why?

7) What advice would you give a government agency tasked with providing support to food-service providers in the implementation of calorie posting?

- What type of support would you like to see them provide? Why?

- What do you think could be done to assist food-service businesses in applying calorie labelling?

\section{Debriefing/conclusion}

1) Comment briefly on the main points of the discussion and ask interviewee if this is the case.

2) Thank the interviewee for their time and effort and ask if they have any questions or anything more to add.

3) Conclude the interview if there are no further questions and reassure participant around the issues of confidentiality, anonymity and privacy, and state that findings will not reveal personal details.

\section{Appendix 2}

Topic guide for food-service businesses not displaying calorie information

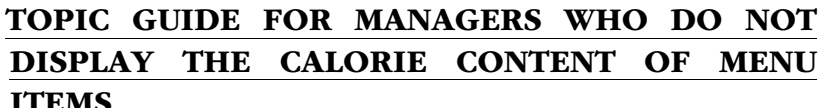

Firstly, I would like to thank you for taking the time to talk to me. My name is ... and I am a research assistant with the Department of Epidemiology and Public Health. I would like to briefly explain the rationale for the interview and, if you are happy to continue with the interview, I will ask you to sign a consent form before we commence the interview.

Rationale: The aim of this research is to investigate the uptake of voluntary calorie posting from a representative sample of food-service businesses in Ireland, to understand the underlying barriers and facilitators in the uptake of calorie labelling and to appreciate the personal opinions and experiences of food-service businesses that apply calorie labelling and inform any further action.

Duration of interview: The interview will take approx. $1 \mathrm{~h}$ and I would just like to check a few details before we get started.

- Would you mind if I record the interview? Anything we discuss will be confidential and your identity will remain anonymous on any reports or publications. Finally, you can stop the interview at any point, if you wish. Do you have any questions before we get started?

- Go through the consent form, sign and give copy.

Before we start the recording, may I ask you to confirm your position within the company and how long you have been working in this role?

\section{When you start recording, outline the following:} This is interview one recorded on ...... (Date/Time)

Opening question: Firstly, I would like to get an understanding of your views on calorie labelling on menus? What is your opinion of calorie labelling on menus (do you agree or disagree with the concept?) 
If menu items do not have calorie posting in place but business is currently preparing its implementation, please ask the following questions:

\section{A) Motivation behind preparing to display calorie labelling}

1) What has motivated you/your company to prepare calorie information on your menu items?

- Who was involved in this decision? Was it solely your decision or a group decision?

- Who did you/the company seek advice from?

- How long did you/the company think about implementing before taking action?

2) When making this decision, what did you/the company consider being the potential benefits of introducing calorie labelling? What did you consider to be the potential risks (pros and cons)?

- Business process, staff and consumer perspectives

- What are you/the company worried about regarding the implementation? Why?

\section{B) Logistics of calorie labelling}

Now I would like to move on to talking about your experience around preparing calorie information for your menu

1) What steps were taken to operationalise the posting of calorie information?

- Who is overseeing this project? Why was this person selected?

2) Where do you think you will get the necessary information from to create the calorie labels? Why do you think you will you use this information source? If in the process of using a particular source, do you find it useful and would you recommend this source?

Probes (if needed):

1. Do you think you will hire/are you hiring a nutritionist to help calorie profile each food? If yes, how will/did you identify this person? Why have you chosen this route to implement calorie labelling?

2. Will/have you or your staff members undertake/ undertaken training on how to calorie profile meals? Why? Who provides this? What is the focus of this training and is it valuable? If not, why not?

3. Will/have you seek/sought specific advice from experts (unpaid)/others who had already introduced such information? What type of information and why will/have you gone to these sources? Is it useful?

4. Do you think you will use/are you using any online tools/technology to help in the calculation of calories? Are you aware of the FSAI MenuCal? What did you think of it? 3) Do you plan to trial your approach with specific dishes or will you calorie profile all dishes at the same time? Why will/are you take/taking this approach?

- Do you intend to apply calorie information to all food and drink items in the same manner?
- Do you envisage any difficulties with different menu options like specials or made-to-order items?

4) How long do you think it will take you to create this calorie information?

- Why?

-What are you finding the most time-consuming?

- Do you think it will impact on your current recipes and menus? Do you think it will affect them? Do you think you will need to standardise/document recipes prior to calculating? Do you think this would be possible in your establishment?

5) What costs do you think will be involved in implementing calorie labelling?

- Approximately how much do you think it will cost the business overall?

- What are the sources of this cost (and relative contribution of each cost source)?

- Will there be ongoing costs?

- Do you think displaying calories will have an effect on your profit margins within the business?

6) As a result of providing this information to your customers do you think you will have to make any changes to: (i) practices in the kitchen and in the ordering of food; (ii) the information you require from suppliers; (iii) the range and types of food you offer your customers?

- Why do you think these changes will be necessary?

7) How confident are you that the calorie information will be accurate, once calculated?

- Have you thought about how you will update calories on amended items?

8) What are the main challenges you are facing in implementing calorie labelling?

- What are you doing to overcome these challenges?

If menu items do not have calorie posting in place and currently business is preparing its implementation, please ask the following questions:

\section{C) Motivation NOT to provide calorie information}

1) What influenced your decision to not implement calorie posting on your menu?

- Have you considered implementing at any stage?

- Have you ever sought advice from anyone regarding the matter?

- Do you believe that your menu offers healthy options? Do you have any thoughts on how many calories are in your menu options?

2) What do you consider to be the potential benefits of introducing calorie labelling? What are the positional risks?

- Business process, staff and consumer perspective

- Do you have concerns over its application?

\section{D) Logistics of calorie labelling}

Now I would like to move on to talking about what you think implementing calorie labelling would involve. 
1) If you were to go down the route of calorie posting, how do you think you would go about getting the necessary information to create the calorie labels?

- Who would you ask for advice?

- Would you create calorie labels internally, or would you source external help?

- Are you aware of any online tools/technology which can assist in calorie calculation? Are you aware of the FSAI MenuCal? Have you tried it/what did you think of it?

2) How much work do you think would be involved in implementing calorie posting in your establishment?

- How much time would you think would be needed to implement? Why? Would you need to standardise and document recipes prior to applying calorie labelling? Do you think this would be possible in your establishment? - What would you envisage the cost to be? What would be the sources of this cost?

3) If you were to provide calorie information to customers, do you think it would be necessary to alter: (i) current kitchen practices; and/or (ii) recipes/menus?

- Why would these changes be necessary?

- Do you think it would be difficult to keep calorie information accurate/up to date?

The following questions are directed at all interviewees:

\section{E) Attitudes towards and perception of calorie labelling}

1) What are your thoughts on the government's proposed regulation regarding making calorie posting on menus mandatory in all food-service outlets?

- What implications (good and bad) do you think this would have on: (i) your establishment; (ii) the food industry; (iii) consumers?
2) How do you think consumers would react/respond to the calorie labelling?

- Do you think consumers read/understand this information? Do you think it influences their food choice? How? Do you think some consumers would rather it not be displayed? 3) Regarding nutrition labelling, do you think it is necessary to provide more than just calorie information to consumers?

- Do you think there is a need to display 'daily calorie needs' or other nutritional information in addition to calories? Why? Where should this information be displayed? What do you think the benefits/drawbacks of this are?

4) Are you familiar with traffic light displays as a means of displaying additional nutrient information like saturated fats, sugars, salt of menu items?

- Do you think this would be beneficial to consumers?

- Do you think this type of display would be understood by consumers/influence their choice?

5) What advice would you give a government agency tasked with providing support to food-service providers in the implementation of calorie posting?

- What type of support would you like to see them provide? Why?

- What do you think could be done to assist food-service businesses in applying calorie labelling?

\section{Debriefing/conclusion}

1) Comment briefly on the main points of the discussion and ask interviewee if this is the case.

2) Thank the interviewee for their time and effort and ask if they have any questions or anything more to add.

3) Conclude the interview if there are no further questions and reassure participant around the issues of confidentiality, anonymity and privacy, and state that the findings will not reveal personal details. 